Research Article

\title{
Determinants of Rice Technical Efficiency in District Nasirabad, Balochistan
}

\author{
Khalid Khan* and Guo Xiangyu
}

College of Economics and Management, Northeast Agricultural University, Harbin, Heilongjiang 150030, China

\begin{abstract}
The study applied the stochastic approach of Cobb-Douglas production function to evaluate the technical efficiency of rice production in Nasirabad, Balochistan. The results of the study vetoed all the hypotheses of technical efficiency. The results indicate that 42 percent of the rice producers are technically efficient and have significant potential for technical efficient rice production. Therefore, there is a great potential to increase the per acre productivity of a typical farmer in the district to a greater extent by achieving the technical efficiency. Moreover, the additional amount of rice obtained with help of technical efficiency improvements can also spur the average income of family to escape them from absolute poverty. Furthermore, the results of the study indicate that extensive consultation and training of the farmers can significantly improve the technical efficiency. In other words, the extension department of Balochistan should take a step to provide all the necessary training and consultation to the farmers to improve the technical efficiency of the rice producers in the district.

Received | March 24, 2020; Accepted | April 13, 2020; Published | May 15, 2020

*Correspondence | Khalid Khan, College of Economics and Management, Northeast Agricultural University, Harbin, Heilongjiang 150030, China; Email: khalidkk82@yahoo.com

Citation | Khan, K. and Xiangyu, G., 2020. Determinants of rice technical efficiency in District Nasirabad, Balochistan. Journal of Innovative Sciences, 6(1): 12-16.

DOI | http://dx.doi.org/10.17582/journal.jis/2020/6.1.12.16

Keywords $\mid$ Stochastic approach, Cobb-douglas production function, Technical efficiency, Rice production
\end{abstract}

\section{Introduction}

A griculture is an important source of both aggregate and household income in developing countries and every single boost in agricultural productivity eventually reduces poverty among farmers and households. In developing countries farmers are heterogeneous, some farmers produce commercially while others just do substance farming. However, in Pakistan almost fifty years after the Green Revolution, farmers are still struggling hard to produce enough food to feed their family and to earn suitable income for the family.

In Pakistan rice is both cash and food crops. It contributes 0.6 percent to the national GDP while 3.0 percent to the GDP agricultural sector. Afterward, it is the one most valuable staple food crop of Pakistan. During the period of 2018-19, the area cultivated under the rice crop is declined by 3.1 percent (from 2,901 thousand hectares in 2017-18 to 2,810 thousand hectares in 2018-19) Wing and Finance (2018). Likewise, the production of rice remained short of 3.3 percent against the target of 7.0 million tones Wing and Finance (2018). Nevertheless, the decline in the production as a result of shrinkage in the cultivated area, scarcity of water, dry weather and climate change. Nonetheless, the per acre productivity of Pakistan is also not overwhelming and quite short from the world average productivity of rice per acre Wing and Finance (2018). There are several plausible explanations for the country's low per acre 
productivity, nonetheless among others, one of the most acceptable rationales is, low technical efficacy.

Moreover, as a result of the growing population, the contemporary economic growth of the country is import oriented which constantly keeps the country foreign exchange reserve limited and under pressure. Furthermore, this situation also puts the self-sufficiency of the country at high risk. Therefore, to attain the objective of self-sufficiency, the country needs, a high production of food grains. As rice is one of the chief food crops of Pakistan. Henceforth, rice production can play a curial role to achieve self-sufficiency in food security. Furthermore, rice production in sturdily connotated with food security in Pakistan.

Moreover, variations in rice productivity has a direct impact on food security, particularly among the households living in rural areas and belong to the lower strata of income. Moreover, this strong association of rice production and food security will have a strong effect on the country's struggle to eliminate extreme hunger and poverty. Likewise, the current escalation in rice prices leads to a food crisis in the country. Moreover, the factors which are responsible for this hike in the rice prices are high population growth, natural disasters, high prices of agricultural inputs, urbanization, land use and the deterioration in the area under agricultural production.

At present, Pakistan is struggling hard to meet the growing demand for staple food. Moreover, the government is taking various initiatives to meet this growing demand for staple food. In this scenario, the production of rice can play a vital role if its production can put on innovative and state of the art lines. Nevertheless, the production of rice is entirely depending on the availability of quality inputs, high yield verities and proper allocation of resources. On the other hand, rice production can be increased by increasing the area under cultivation. Moreover, it will be much better to increase the production of rice vertically rather than horizontally.

The technical efficiency of rice productivity can play an important role to improve the total yield of farmers and reduce poverty, particularly in rural areas. Furthermore, elevated productivity can help to upsurge income and safeguard food security, particularly in the case of small farmers who fully relying on rice production.
The adoption of modern technologies and thirdgeneration hybrid rice, farmer training, the use of high-quality seeds and modern agricultural tools can support rice production in Pakistan. This argument raises the question that how Pakistan will be achieved the optimum level of rice production with elevated technical efficiency. Hereafter to answer this question, the study analyzes the key factors behind rice productivity and technical efficiency in district Nasirabad, Balochistan. Nasirabad is considered the green belt and lifeline of Balochistan agriculture production.

Rice is grown in those area where availability of water in high. Generally, rice is grown in rural areas of the Nasirabad region of Balochistan which play an important role for agricultural communities. So far, no research has been conducted to analyze the determinants of the rice technical efficiency in the district. The main objective of this study is to find out the factors which plays important role in the technical efficiency of rice. Moreover, improving rice technical efficiency can help to intensify aggregate production activities, surge farmers' incomes and reduce poverty, particularly in the district.

\section{Materials and Methods}

In general, the change in production due to technical inefficiencies and random shocks, which can be apprehended by a stochastic production frontier approach (SPFA). Moreover, inefficient production leads to inefficient use of scarce resources. The present study addresses technical inefficiencies in rice production. Further, technical efficiency (IT) can be projected via different approaches, the most notable among them are Data Envelopment Analysis (DEA) and SPFA. Nonetheless, it is well documented, that the DEA assumes that there are no random blocks in the data set. As farmers continue to operate under uncertain conditions. However, the current study uses SPFA led by Aigner et al. (1977); and Meeusen and van den Broeck (1977). The specification, of SPFA can be penned as:

$$
Y_{i}=F\left(X_{i}, \beta\right) e^{\epsilon_{i}}
$$

Where; $Y_{i}$ is the rice output, $X$ is a vector of the determinants s of technical efficiency and $\beta$ is a vector of $\mathrm{k}$ unknown parameters, while $\varepsilon_{i}$ shows a stochastic error. Moreover, normally the stochastic production 
frontier is an also known as a "composed error" model, since it proposes that the error term of the model is disintegrated into two elements: a stochastic random shocks and a technical inefficiency element which can be specified as follows:

$$
\varepsilon_{i}=v_{i}-u_{i} \quad \ldots .(2)
$$

where $v i$ is a normally distributed error term that encapsulates both the shock of factors that are in control of the farmers such the weather, natural disaster, and luck measurement errors, and other random error. It is presumed that $v i$ is normally distributed, therefore the production frontier is stochastic. The two error components $(v i, u i)$ are also presumed to be independent of each other and hence the variance parameters of the model can be parameterized as:

$$
\sigma_{s}^{2}=\sigma_{v}^{2}+\sigma_{u}^{2} ; \gamma=\frac{\sigma_{u}^{2}}{\sigma_{v}^{2}} \text { and } 0 \leq \gamma \leq 1 \quad \ldots(3)
$$

Where; it explains that the total variation in the dependent variable caused by technical inefficiency and random shocks at the same time. Hence forward:

$$
\begin{gathered}
Y_{t}=F\left(X_{i}, \beta\right)=Y_{e^{-u_{i}}} e^{-v_{2}} \\
e^{-u_{i}}=\left[\frac{Y_{i}}{F\left(X_{i}, \breve{\beta}\right) e^{v_{i}}}\right] \ldots(4) \\
I E_{i}=F\left(Z_{i}\right) \quad \ldots .(6)
\end{gathered}
$$

Finally, following Hussain et al. (2011); Khan and Ghafar (2013); Wahid et al. (2017); Mamary et al. (2018); Memon et al. (2015) and Khan et al (2019) the specification of the Cobb-Douglas function is quantified in Equation 7.

$\ln Y_{t}=\beta++\beta_{1} \ln X_{1}+\beta_{2} \ln X_{2}+\beta_{3} \ln X_{3}+\beta_{4} \ln X_{4}+\beta_{5} \ln X_{5}+\beta_{6} \ln X_{6}+\varepsilon_{t} \ldots(7)$

Where; Yt $=$ rice output, $\mathrm{X} 1=$ Cultivated Area of Rice, $\mathrm{X} 2=$ Fertilizer, $\mathrm{X} 3=$ Quality Seed, $\mathrm{X} 4=$ Hired Labor, $\mathrm{X} 5=$ Irrigation X6 $=$ Cost of Machinery $\varepsilon t=$ Residual term. However, for technical inefficiency model the study consider Khan and Ghafar (2013), Wahid et al. (2017).

$u_{i}=\alpha_{0}$ Eucation $+\alpha_{1}$ Age $+\alpha_{2}$ Quality of soil $+\alpha_{3}$ Experiance +

$\alpha_{4}$ Distance from main Chamel $+\alpha_{5}$ Distance from farm to marke $+\varepsilon_{t} \ldots$ (8)

All of the variables of Equation 8 are self-explanatory. Moreover, the Equation 8 defining the impact of technical inefficiency in its typical form as a linear Journal of Innovative Sciences

June 2020 | Volume 6 | Issue 1 | Page 14 function of socioeconomic and management factors. However, the complete aspect of the dependent and independent variables is highlighted. The data was collected from the district by the following process through random sampling (Khan et al., 2018b).

$$
\begin{gathered}
\text { Sample size form Baba Kot }=\frac{n}{N} \times N_{i}=[200 / 147,160] \times 14,837=20 \\
\text { Sample size form Chattar }=\frac{n}{N} \times N_{t}=[200 / 147,160] \times 22,599=31 \\
\text { Sample size form Dera Murad Nasirabad }=\frac{n}{N} \times N_{i}=[200 / 147,160] \times 70,374=96 \\
\text { Sample size form Tambo }=\frac{n}{N} \times N_{t}=[200 / 147,160] \times 147,160=53
\end{gathered}
$$

Where; $\mathrm{N}=$ Total number of the farmer in the targeted (population), NI= Number of the respondents in each village, $\mathrm{n}=$ Total sample size i.e. $200, \mathrm{Ni}=$ Total number of the farmer in each village.

\section{Results and Discussion}

The results of the maximum likelihood techniques (MLE) are shown in Table 1. In the stochastic frontier model, majority of the variables are statistically significant and have an appropriate impact on output as stipulated by the literature. It implies that inputs are playing an important role in the output determination. Moreover, the parameters of the stochastic frontier Cobb-Douglas production function can be directly represented as output elasticity.

The results show that the maximum elasticity of the labor costs and irrigation are (0.18) and, (0.13). Both variables are carrying significant coefficients and have a clear positive impact on rice productivity. The elevated elasticity of labor and irrigation implies that the impact of total factor productivity is dominant. Hence, a one percent increase in the use of labor and irrigation implies the production of rice will spur by 0.18 and 0.13 percent respectively. The consequent increase in productivity is subject to the timely availability of water for irrigation, good seeds and the cost of machinery. Another important contribution to rice production is the use and acquisition of cultivated area under rice, quality seeds, and fertilizers, where a $1 \%$ surge in the surface area of the rice and quality seeds increase rice production by $0.11 \%$ and $0.12 \%$ respectively. Moreover, a one percent increase in the fertilizers can strengthen rice productivity by $0.06 \%$. Similarly, in the technical inefficiency model, the distance from farm to market is carrying a negative sign but statistically insignificant while the coefficient 
of distance from farm to the main channel shows that when the distance is increasing, it boosts the technical inefficiency of rice by 09\%. Similarly, age and education have a positive and negative impact on rice technical inefficiency respectively. Likewise, the quality of soil also discourages technical inefficiency. Table 2 officers the values of average, maximum, minimum and frequency distribution of technical efficiency of the rice producers. The mean, maximum, and minimum values of the technical efficiency are $75 \%$, $95 \%$, and $73 \%$ respectively. Moreover, a vital majority of individual technical capability is between $86-90 \%$ while just $7 \%$ of the farmers have $95 \%$ of technical efficiency.

Table 1: Estimates of OLS.

\begin{tabular}{lll}
\hline Stochastic frontier model & & \\
\hline Intercept & 1.201 & $5.015^{*}$ \\
cultivated area of rice & 0.214 & $3.11^{* *}$ \\
Fertilizer etc & -0.002 & -1.345 \\
Seed price & 0.120 & 2.981 \\
Hired labor & 0.187 & 1.020 \\
Cost of Machinery & 0.002 & 1.670 \\
Irrigation & 0.102 & 4.231 \\
Stochastic frontier model & & \\
Intercept & -0.106 & 0.921 \\
Aggregate farmed area & -0.84 & 0.309 \\
Age & 0.010 & 0.99 \\
Education & 0.010 & 0.89 \\
Quality of soil & -0.045 & $-4.07^{*}$ \\
Family labour & -0.201 & $-3.90^{* *}$ \\
Distance from main channel & -0.098 & $-5.90^{* * *}$ \\
Irrigation type & 0.001 & 0.13 \\
Distance from village to city & 0.012 & 1.23 \\
Variance parameters & & \\
Sigma-square ( $\sigma 2)$ & 0.130 & \\
Ln Likelihood & 55.569 & \\
\hline
\end{tabular}

Table 2: Likelihood-ratio tests.

\begin{tabular}{lllll}
\hline $\begin{array}{l}\text { Null Hypoth- } \\
\text { esis }\end{array}$ & $\mathbf{H}_{\mathbf{0}}: \boldsymbol{\gamma}=\mathbf{0}$ & $\begin{array}{l}\mathbf{H}_{\mathbf{0}}: \boldsymbol{\gamma}=\boldsymbol{\delta}_{\mathbf{0}} \\
=\boldsymbol{\delta}_{\mathbf{1}}=\mathbf{0 0}\end{array}$ & $\begin{array}{l}\mathbf{H}_{\mathbf{0}}: \boldsymbol{\gamma}=\boldsymbol{\delta}_{\mathbf{0}} \\
=\boldsymbol{\delta}_{\mathbf{1}}=\mathbf{0 0}\end{array}$ & $\begin{array}{l}\mathbf{H}_{\mathbf{0}}: \boldsymbol{\gamma}=\boldsymbol{\delta}_{\mathbf{0}} \\
=\boldsymbol{\delta}_{\mathbf{0}}=\mathbf{0 0}\end{array}$ \\
\hline Log likelihood & 98.00 & 45.01 & 45.12 & 33.52 \\
LR Statistics & 23.01 & 32.00 & 37.09 & 28.09 \\
Critical Value & 14.07 & 25.00 & 25.00 & 25.00 \\
Decision & $\begin{array}{l}\text { All the null hypotheses rejected simultane- } \\
\text { ously }\end{array}$ & \multicolumn{4}{l}{} \\
\hline
\end{tabular}

\section{Conclusions and Recommendations}

The purpose of this study is to assess the factors Journal of Innovative Sciences

June 2020 | Volume 6 | Issue 1 | Page 15 affecting rice productivity at the farm level and the technical performance of rice production in Nasirabad. To perform the technical efficiency analysis, a stochastic frontier production function was used. The estimated production efficiency measured by the overall efficiency index ranges from 56.3 percent to 98.9 percent, with an average technical efficiency of $81.2 \%$. The results show that the average technical performance in TIS is much lower than in IIS. IIS technical performance is more efficient than TIS because IIS technical performance is 76.7 to 98.9 percent, on average 87.0 percent, while TIS technical performance is 75.4 percent, from 56.3 percent on average to 90,3 percent.

\section{Authors Contribution}

Khalid Khan has completed this study under the supervision of Professor Dr. Guo Xiangyu, NEAU, Harbin.

\section{Conflict of interest}

The authors have declared no conflict of interest.

\section{References}

Aigner, D., Lovell, C.K. and Schmidt, P., 1977. Formulation and estimation of stochastic frontier production function models. Journal of Econometrics, 6(1): 21-37. https://doi. org/10.1016/0304-4076(77)90052-5

Bunnika, P., Khan, K., and Xiangyu, G., 2019. An Empirical Analysis of Battambang Agricultural Cooperatives Efficiency in Cambodia. Sarhad Journal of Agriculture, 35(4): 1094-1098. https://doi.org/10.17582/journal. sja/2019/35.4.1094.1098

Hussain, N., Shahid, A., Naveed, M. and Muhammad, S., 2011. An estimation of technical efficiency of garlic production in Khyber Pakhtunkhwa Pakistan. Int. Food Agric. Econ., 2(2): 169-178.

Khan, K., Kamal, M.A., Ramazan, S., Khan, G., Ali, G. and Ahmed, S., 2018. Impact of Agricultural Credit on Livestock Income: A Case Study of District Lasbela, Balochistan. Sarhad Journal of Agriculture, 34(2): 1389-1392. https://doi. org/10.17582/journal.sja/2018/34.2.246.250

Khan, K., Liaqat, S., Rasheed, S., and Kakar, I., 2018. Nexus between livestock income and rural livelihood: A case study of Lasbela, Balochistan. Journal of Innovative Sciences, 4(2): 
90-94. https://doi.org/10.17582/journal. jis/2018/4.2.90.94

Khan, K., Yousaf, H., Mohammad, N., Khan, M. and Thao, D.T., 2019. Nexus between money supply and food prices: An empirical evidence from China. Journal of Innovative Sciences, 5(1): 36-39. https://doi.org/10.17582/journal. jis/2019/5.1.36.39

Khan, K., Khan, G., Shaikh, S.A., Lodhi, A.S. and Jilani, G., 2015. ARIMA Modelling for Forecasting of Rice Production: A Case Study of Pakistan. Lasbela University Journal of Sciences and Technology, 4(1): 117-120.

Memon, M.H., Khan, K., Abbass, M.Y., Khan, G., and Kamal, M.A., 2015. Impediments to technology adoption: A case study of peach production in District Swat, Pakistan. Journal of Managerial Sciences, 9(2): 226-242.

Mamary, K.A., Lagat, J.K., Lan, J.K., Hussain, N., Shahid, A., Naveed, M. and Muhammad,S., 2011. An estimation of technical efficiency of garlic production in Khyber Pakhtunkhwa

Pakistan. Int. Food Agric. Econ., 2(2): 169-178

Meeusen, W., and van Den Broeck, J., 1977. Efficiency estimation from Cobb-Douglas production functions with composed error. International Economic Review, pp. 435444. https://doi.org/10.2307/2525757

Shaikh, S.A., Hongbing, O., Khan, K., and Ahmed, M., 2016. Determinants of Rice Productivity: An Analysis of Jaffarabad District-Balochistan (Pakistan). European Scientific Journal, 12(13): 41-50. https://doi.org/10.19044/esj.2016. v12n13p41

Wahid, U., Ali, S. and Hadi, N.A., 2017. On the estimation of technical efficiency of tomato growers in Malakand, Pakistan. Sarhad J. Agric. 33(3): 357-365. https://doi.org/10.17582/ journal.sja/2017/33.3.357.365

Wing, E.A.S., and Finance, D., 2018. Economic Sur. Economic Survey, 2018. pp. 16. 